JURNAL EKONOMI

EFEKTIF
ISSN : $2622-8882$, E-ISSN : 2622-9935

Jurnal Ekonomi Efektif, Vol. 2, No. 1, Oktober 2019

@.Prodi Manajemen Fakultas Ekonomi Universitas

Pamulang

\title{
PENGARUH KUALITAS PELAYANAN DAN PROMOSI TERHADAP KEPUASAN KONSUMEN PADA ALFAMART RODA HIAS SERPONG
}

\author{
Nurmin Arianto \\ dosen01118@unpam.ac.id
}

\begin{abstract}
ABSTRAK
Masih terdapat keluhan konsumen yang komplain setiap bulannya terjadi peningkatan, dikarenakan adanya faktor-faktor yang mempengaruhi banyaknya komplain konsumen pada setiap bulannya. Jika dilihat dari jenis komplain maka komplain yang terbanyak ialah pada "proses penempatan barang yang kurang rapih" sehingga pelayanan yang diberikan masih kurang maksimal dan menyebabkan kepuasan konsumen ikut menurun. Tujuan dari penelitian ini adalah untuk mengetahuipengaru kualitas pelayanan dan promosibaik secara parsial ataupun simultan terhadap kepuasan konsumen.

Analisis data yang digunakan dalam penelitian ini menggunakan uji validitas, reliabilitas, asumsi klasik dan regresi linear berganda, sedangkan populasi dalam penelitian ini adalah konsumen yang berbelanja sedangkan jumlah sampel ialah sebanyak 100 Konsumen.

Dari hasil penelitian maka Terdapat pengaruh yang positif dan signifikan antara kualitas pelayanan terhadap kepuasan konsumen, Terdapat pengaruh yang positif dan signifikan antara promosi terhadap kepuasan konsumen, Terdapat pengaruh yang positif dan signifikan secara simultan antara Kualitas Pelayanan dan Promosi terhadap Kepuasan Konsumen.
\end{abstract}

\section{Kata Kunci : Kualitas Pelayanan, Promosi, dan Kepuasan}

\section{ABSTRACT}

There are still consumer complaints that complaints increase every month, due to factors that affect the number of consumer complaints every month. When viewed from the type of complaint, the most complaints are in the "process of placing goods that are less tidy" so that the services provided are still less than optimal and cause consumer satisfaction to decline. The purpose of this study is to determine the quality of service and promotion, either partially or simultaneously, to customer satisfaction.

Analysis of the data used in this study used validity, reliability, classic assumptions and multiple linear regression tests, while the population in this study was consumers who shop while the number of samples is 100 consumers.

From the results of the study found a positive and significant influence between the quality of service to customer satisfaction, There is a positive and significant effect between promotion of customer satisfaction, There is a positive and significant effect simultaneously between Service Quality $i$ and Promotion $i$ on Consumer Satisfaction.

\section{Keyword : Service Quality, Promotion, and Satisfaction}




\section{PENDAHULUAN}

\section{A. Latar Belakang Masalah}

Perkembangan pusat perbelanjaan sekarang diikuti oleh munculnya pusat perbelanjaan modern, termasuk Alfamart Roda Hias Serpong.

Kemampuan perusahaan dalam memberikan pelayanan merupakan salah satu penentu keberhasilan suatu perusahaan karena pelayanan dapat menentukan seberapa besar konsumen akan menentukan pilihan untuk membeli produk sesuai dengan kebutuhan yang diinginkan.

Pengelola dan jajaran dari Alfamart Roda Hias Serpong harus memiliki keseragaman aksi dalam upaya memberikan pelayananyang terbaik bagi konsumensehingga dapat meningkatkan kepuasan konsumendan mau untuk kembali untuk membeli produk yang tersedia di Alfamart Roda Hias Serpong. Berikut data yang berkaitan dengan jumlah komplainyang pada Alfamart Roda Hias Serpong, periode Juni-Oktober sebagai berikut:

Tabel 1.1

Data Komplain Konsumen

\begin{tabular}{|l|c|c|c|c|c|c|}
\hline Jenis Complain & Juni & Juli & Agst & Sept & Okt & $\begin{array}{c}\text { Jumlah Jenis } \\
\text { Komplen }\end{array}$ \\
\hline Karyawan kurang ramah & 3 & 2 & 4 & 2 & 3 & 14 \\
\hline Penempatan barang yang kurang rapi & 3 & 3 & 3 & 3 & 3 & 15 \\
\hline Tempat parkir yang kurang memadai & 1 & 2 & 3 & 2 & 1 & 9 \\
\hline Kebersihan toko yang kurang terjaga & 3 & 2 & 2 & 3 & 2 & 12 \\
\hline Lambatnya penanganan komplain & 3 & 2 & 3 & 3 & 2 & 13 \\
\hline Total Komplen Perbulan & 12 & 11 & 15 & 13 & 11 & 62 \\
\hline
\end{tabular}

Sumber : Alfamart Roda Hias Serpong

Karena itu dilihat dari tabel di atas data keluhan konsumen yang komplain setiap bulannya terjadi peningkatan, dikarenakan adanya faktor-faktor yang mempengaruhi banyaknya komplain konsumen pada setiap bulannya. Jika dilihat dari jenis komplain maka komplain yang terbanyak ialah pada "proses penempatan barang yang kurang rapih" sehingga pelayanan yang diberikan masih kurang maksimal dan menyebabkan kepuasan konsumen ikut menurun. Melihat kondisi tersebut, pada saat ini para perusahaan berusaha memberikan kualitas pelayanan yang baik untuk menarik konsumen.

Adapun yang menyebabkan konsumen menjadi kurang puas antara lain masalah pelayanan pegawai yang kurang ramah, produk-produk yang kurang tertata rapi, serta kecepatan didalam menangani keluhan konsumen yang kurang efektif. Pemahaman terhadap pemenuhan keinginan konsumen merupakan syarat peningkatan mutu dan produktifitas secara terus menerus dalam mencapai kepuasan total konsumen.

Promosi ini terkait dengan berbagai kegiatan yang dilakukan oleh perusahaan untuk mencoba menjalin komunikasi antara kualitas produknya dan untuk membujuk konsumen untuk membeli produk tersebut.

Berikut adalah data promo apa saja yang dilakukan oleh Alfamart Roda Hias Serpong untuk menarik konsumen:

Table 1.2

Data jenis promosi yang ada di Alfamart Roda Hias Serpong

\begin{tabular}{|c|c|c|c|c|}
\hline Juni & Juli & Agustus & September & Oktober \\
\hline Beli 1 gratis 1 & Beli 2 gratis 1 & Beli 2 gratis 1 & Beli 2 bayar 1 & Beli 2 gratis 1 \\
\hline Beli 2 bayar 1 & Beli 2 bayar 1 & Beli 1 gratis 1 & Beli 1 gratis 1 & Beli 2 bayar 1 \\
\hline Belanja & Harga cuci & Beli 2 bayar 1 & Belanja & Harga cuci \\
100.000 & gudang & & 100.000 & gudang \\
mendapatkan & & & mendapatkan & \\
\hline
\end{tabular}




\begin{tabular}{|c|c|c|c|c|}
\hline $\begin{array}{c}\text { voucher } \\
\text { belanja 50.000 }\end{array}$ & & & $\begin{array}{c}\text { voucher } \\
\text { belanja 50.000 }\end{array}$ & \\
\hline Potongan harga & Potongan & Potongan & Potongan & Potongan harga \\
$30 \%$ khusus & harga 30\% & harga 30\% & harga 30\% & $30 \%$ khusus yang \\
yang & khusus yang & khusus yang & khusus yang & mempunyai kartu \\
mempunyai & mempunyai & mempunyai & mempunyai & member Alfamart \\
kartu member & kartu member & kartu member & kartu member & \\
Alfamart & Alfamart & Alfamart & Alfamart & \\
\hline
\end{tabular}

Sumber: Alfamart Roda Hias Serpong

Dengan berbagai macam promosi yang dilakukan oleh Alfamart Roda Hias Serpong agar bisa menarik konsumen supaya bisa tertarik untuk berbelanja di Alfamart Roda Hias Serpong, dari data tersebut dapat diketahui bahwa kegiatan promosi yang dilakukan oleh Alfamart Roda Hias Serpong masih kurang optimal dan promosi produk yang dilakukan masih kurang menarik konsumen sehingga menyebabkan kepuasan konsumen ikut menurun.

Kondisi ini menggambarkan bahwa pelayanan itu sangat penting bagi perusahaan yang persaingan usahanya sejenis, apalagi produk-produk yang dijual di pasar itu sangat banyak dan beranekaragam, sehingga masih kurang optimalnya promosi yang digunakan perusahaan untuk dapat lebih menarik jumlah konsumen yang berkunjung untuk berbelanja. Selain promosi masih ada yang kurang optimal yang digunakan oleh perusahaan, salah satu nya kualitas pelayanan yang diberikan juga dirasa masih kurang efektif dimana masih ada beberapa konsumen yang mengeluh tentang pelayanan yang diberikan saat berbelanja di Alfamart Roda Hias Serpong, sehingga hal tersebut dapat mengakibatkan menurunnya tingkat kepuasan dari konsumen. Secara garis besar beberapa gejala tersebut diantaranya pelayanan masih ditemukan kekurangan dengan banyaknya komplain dari konsumen, promosi produk yang kurang tertarik dan tidak menarik konsumen dan jumlah konsumen perusahaan setiap tahunnya berfluktuatif.

Menunjuk pada kondisi yang dikemukakan diatas maka penulis akan melakukan penelitian dengan judul "Pengaruh Kualitas Pelayanan dan Promosi Terhadap Kepuasan Konsumen Pada Alfamart Roda Hias Serpong

\section{B. Pokok-pokok Permasalahan}

Berdasarkan identifikasi masalah dan keterbatasan masalah di atas, rumusan masalah adalah sebagai berikut:

1. Apakah terdapat pengaruh kualitas pelayanan terhadap kepuasan konsumen pada Alfamart Roda Hias Serpong?

2. Apakah terdapat pengaruh promosi terhadap kepuasan konsumen pada Alfamart Roda Hias Serpong?

3. Apakah terdapat pengaruh kualitas pelayanan dan promosi terhadap kepuasan konsumen pada Alfamart Roda Hias Serpong?

\section{KAJIAN PUSTAKA}

\section{A. Kualitas Pelayanan}

Kotler dalam Tjiptono\& Chandra (2011:17), Setiap tindakan atau perbuatan yang dapat ditawarkan oleh suatu pihak kepada pihak lain yang pada dasarnya bersifat intangible(tidak berwujud fisik) dan tidak menghasilkan kepemilikian sesuatu.

\section{B. Promosi}

Promosi itu sendiri merupakan aktivitas yang mengkomunikasikan keunggulan produk dan membujuk pelanggan untuk membeli produk itu, Kotler dan Amstrong (2014:77). 


\section{Kepuasan Konsumen}

Kotler (2010:20) mengatakan bahwa "kepuasan konsumen adalah senang atau kecewa seseorang yang muncul setelah membandingkan antara kinerja (hasil) produk yang dipikirkan terhadap kinerja yang diharapkan".

\section{Kerangka Berpikir Penelitian}

Sugiyono (2014:90) mengemukakan bahwa "seorang peneliti harus menguasai teori-teori ilmiah sebagai dasar menyusun kerangka pemikiran yang membuahkan hipotesis".Kerangka pemikiran merupakan penjelasan sementara terhadap kendala yang menjadi objek permasalahan".

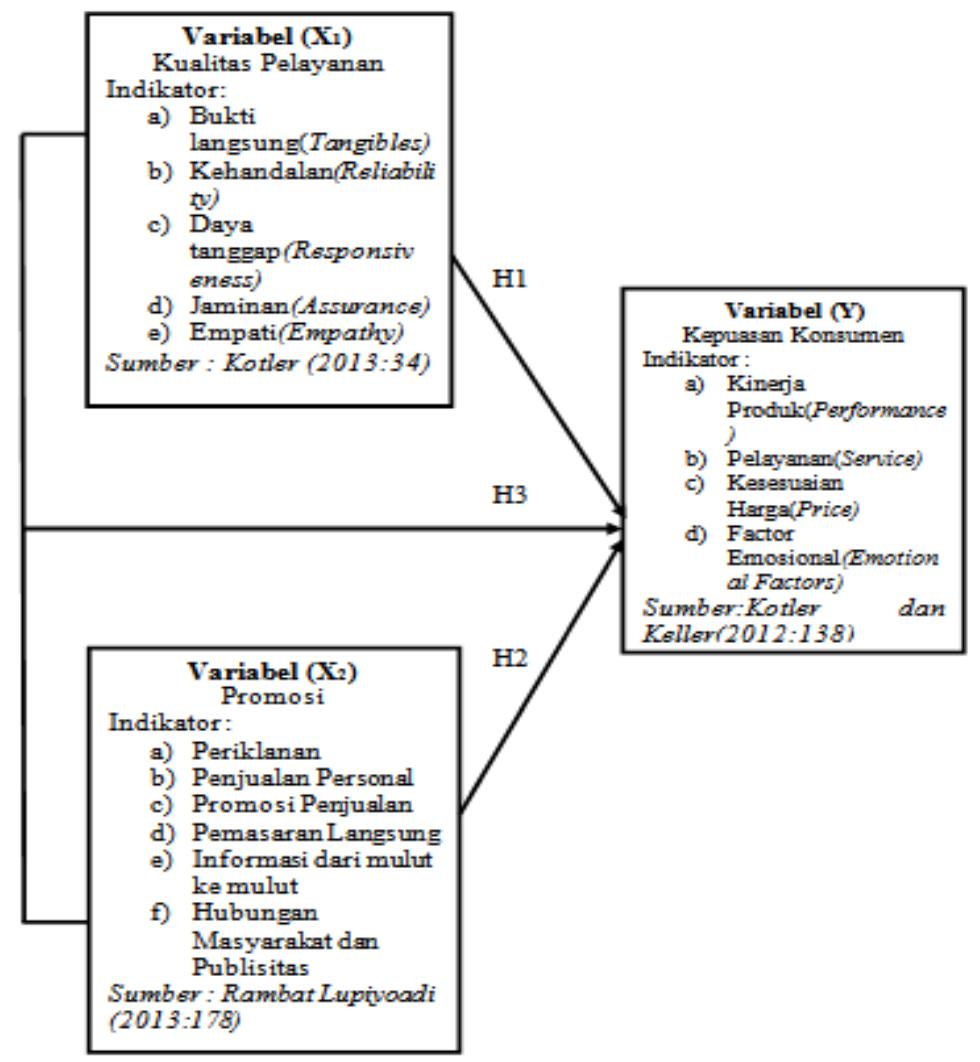

\section{Gambar 2.1 \\ Kerangka Berfikir}

\section{E. Hipotesis}

Adapun rumusan hipotesis yang dibuat adalah sebagai berikut:

$\mathrm{H}_{1}$ : Diduga terdpaat pengaruh antara kualitas pelayanan terhadap kepuasan konsumen pada Alfamart Roda Hias Serpong.

$\mathrm{H}_{2}$ : Diduga terdpaat pengaruh antara promosi terhadap kepuasan konsumen pada Alfamart Roda Hias Serpong.

$\mathrm{H}_{3}$ : Diduga terdpaat pengaruh antara promos dan kualitas pelayanan terhadap kepuasan konsumen pada Alfamart Roda Hias Serpong.

\section{METODE PENELITIAN}

\section{A. Sifat Penelitian}

Metode penelitian yang digunakan dalam penelitian ini adalah dengan metode asosiatif, dimana Sugiyono (2015:11) mengatakan"penelitian asosiatif penelitian yang bertujuan untuk 
mengetahui pengaruh ataupun juga hubungan antara dua variabel atau lebih." Dalam penelitian ini, metode asosiatif digunakan untuk mengetahui pengaruh Kualitas Pelayanan dan Promosi Terhadap Kepuasan Konsumen pada Alfamart Roda Hias Serpong

\section{B. Populasi Dan Sample}

Adapun populasi dalam penelitian ini adalah konsumen yang menggunakan jasa retail di Alfamart Roda Hias Serpong dari bulan Juni s/d bulan Oktober, sebanyak 19.856 konsumen.

Dari teknik sampling tersebut, maka penulis memilih Sampling Aksidental. Pengertian sampling aksidental menurut Sugiyono (2010:85) adalah sebagai berikut: "Sampling aksidental adalah teknik penentuan sampel berdasarkan kebetulan, yaitu siapa saja yang secara kebetulan bertemu dengan peneliti dapat digunakan sebagai sampel, bila dipandang orang yang kebetulan ditemui itu cocok sebagai sumber data. Dengan jumlah 100 Responden. Menggunakan rumus Slovin dengan error sebesar $10 \%$.

\section{ANALISIS DATA}

Analisa data yang digunakan adalah analisa deskriptif dan analisa statistic infrensial dimana untuk mengetahui bayangan umum respnden dan menjawab pertanyaan yang diajukan dalam sebuah penelitian dengan cara menganalisa serta menguji model tersebut secara empiris dengan menggunakan multiple regression dan program SPSS V. 22.

\section{A. Hasil Analsis}

Dari hasil penyebaran kuisioner maka diketahui mayoritas dalam penelitian ini adalah responden dengan jenis kelamin perempuan yaitu sebanyak $63 \%$, sedangakn berdasarkan usia maka rata-rata dibawah 25 th dengan mayoritas masing-masing pekerjaan adalah Mahasiswa yaitu sebanyak $30 \%$.

Jika dlihat dari hasil analsiis deskriptif variable kualitas pelayanan dinyatakan Baik karena diperoleh nilai rata-rata yaitu 3,80berada di kategori skala $(3,41-4,20$ : Baik) dan dilihat dari skor tertinggi 3,88 yaitu pada pertanyaan "Pramuniaga memberikan perhatian dan bantuan pada konsumen sampai konsumen mendapatkan barang yang dicari " hal ini membuktikan bahwa petugas sudah menunjukan rasa empati nya terhadap kosumne yang berbelaja di Alfamart. Disamping itu pihak Alfamart harus lebih meningkatkankualitas pelayanan dari segi“Penempatan barang ditoko yang rapih sehingga konsumen mudah untuk mencari barang yang dicari" dimana diperoleh skor terendah 3,69. Maka dari sebaik nya pada saat datang barang dan akan didisplay barang sebaik nya dilakukan pada saat toko dalam keadaan sepi sehingga barang yang ada di Alfa terlihat rapi dan toko terlihat bersih.

Jika dilihat dari hasil analisis deskriptif maka promosi dinyatakan baik, di lihat nilai ratarata yaitu 3,75berada di kategori skala $(3,41$ - 4,20: Baik ) dimana tanggapan responden terhadap variabel Promosi $\left(\mathrm{X}_{2}\right)$ memiliki kategori skala Baik,dilihat dari skor tertinggi 4,08 yaitu pada petanyaan "Pramuniaga menjelaskan dengan detail barang yang dijual apabila konsumen meminta informasi tentang barang yang dimaksud" Berdasarkan hasil penelitian membuktikan bahwa pramuniaga sudah menunjukan Aspek penjualan penjualan personal, karena sudah berushaa menjelaskan barang yang dibeli konsumen secara detail baik kegunaan dan kekurangan dari barang yang dibeli oleh konsumen.Disamping itu pihak Alfamart harus lebih meningkatkanpromosi dari segi“"Bagi konsumen yang memiliki kartu member akan mendapatkan potongan harga pada produk tertentu" dimana diperoleh skor terendah 3,61.Karena masih banyak konsumen yang menggunakan kartu member untuk produk yang di berikan potongan harga ketersediaannya masih kurang. Maka dari itu sebaiknya Alfamart harus menyediakan stock barang yang mendapatkan potongan harga sehingga konsumen tidak merasa kecewa. 
Dari hasil analisis deskriptif kepuasan konsumen maka terlihat nilai rata-rata yaitu 3,95 berada di kategori skala (3,41 - 4,20: Baik ) dimana tanggapan responden terhadap variabel Kepuasan Konsumen (Y) memiliki kategori skala Baik,dilihat dari skor tertinggi 4,11 yaitu pada petanyaan "Konsumen merekomendasikannya kepada sanak saudara, teman atau tetangga karena pelayanan yang baik dan informasi produk yang sesuai dari para pramuniaga" Berdasarkan hasil penelitian membuktikan bahwa banyak konsumen yang mengakui mereka merasa puas dan merekomendasikannya kepada orang lain. Disamping itu pihak Alfamart harus lebih menaikan kepuasan konsumen karena masih terdapat skor rendah yaitu 3,74 pada Indikator pelayanan dimana "Ketepatan dan kesigapan pramuniaga dalam melayani konsumen sehingga konsumen merasa puas". Hal ini menandakan bahwa pramuniaga masih kurang sigap terhadap konsumen sehingga sebaiknya Alfamart lebih memperhatikan Pramuniaganya agar mereka bisa bersikap lebih sigap terhadap konsumen yang datang dan berbelanja di Alfamart.

\section{B. Uji Validitas dan Reliabilitas}

\section{Uji Validitas}

Dari hasil uji validitas yang dilkukan semua instrument kuisioner variabel kualitas pelayanan, promosi dan kepuasan dinyatakan Valid karena nilia $r$ hit $>r$ tabel seperti instrument kuisioner variabel kualitas pelayanan no 1 diperoleh nilai $r$ hit $0,328>0,300$ sejalan dengan teori Sugiyono (2013:182). Begitupun untuk variabel promosi dan kepuasan konsumen.

\section{Uji Relibilitas}

Dari hasil analisis uji relibilitas maka variabel kualitas pelayanan, promosi dan kepuasan diperoleh nilai $r$ ca $>r$ tabel dimana nilia $r$ ca kualitas pelayanan $0,634>0,600$ dan ini sejalan dengan teori Sugiyono (2013:184). Begitupun untuk variabel promosi dan kepuasan konsumen.

\section{Analisis Regresi Linear Berganda}

Dari hasil analisis data dengan menggunakan SPSS maka diperoleh nilai:

Tabel 4.1

Hasil Pengolahan Multiple Regression Variabel Kualitas Pelayanan $\left(\mathrm{X}_{1}\right)$ dan Promosi

$\left(\mathbf{X}_{2}\right)$

Coefficients $^{\mathrm{a}}$

\begin{tabular}{|c|c|c|c|c|}
\hline \multirow{2}{*}{\multicolumn{2}{|c|}{ Model }} & \multicolumn{2}{|c|}{ Unstandardized Coefficients } & \multirow{2}{*}{$\frac{\text { Standardized Coefficients }}{\text { Beta }}$} \\
\hline & & B & Std. Error & \\
\hline \multirow[t]{3}{*}{1} & (Constant) & 10.417 & 4.370 & \\
\hline & Variabel X1 & .526 & .133 & .424 \\
\hline & Variabel X2 & .243 & .134 & .195 \\
\hline
\end{tabular}

a. Dependent Variable: Variabel $\mathrm{Y}$

Sumber: Data Primer, diolah dengan SPSS

$$
\mathbf{y}=\mathbf{1 0 , 4 1 7}+\mathbf{0 , 5 2 6}\left(\mathrm{X}_{1}\right)+\mathbf{0 , 2 4 3}\left(\mathrm{X}_{2}\right)
$$

Dari hasil tersebut diperoleh nilai konstantan sebsar 10,417 yang artinya jika kualitas pelayanan $\left(\mathrm{X}_{1}\right)$ dan promosi $\left(\mathrm{X}_{2}\right)$ nilai nya 0 , maka kepuasan konsumen nilainya 10,417 dengan asumsi variabel-varaibel lain nya dianggan tetap. Sehingga konsumen akan tetap mesara puas sekalipun kualitas pelayanan dan promosi yang diberikan masih kurang . Dan nilai koefisien variabel kualitas pelayanan. $\left(\mathrm{X}_{1}\right)$ diperoleh sebesar 0,526 dengan tanda yang psotif artinya jika variabel independen lain nilainya tetap dan kualitas pelayanan mengalami kenaiakn satu, maka kepuasan konsumen (Y) akan mengalami kenakaian sebesar 0,526, jadi semakin baik kualitas pelayanan maka semakain naik kepuasan konsumen, serta nilai koefieisn variabel promosi $\left(\mathrm{X}_{2}\right)$ diperoelh sebesar 0,243 dengan tanda postif artinya jika variabel 
independen lainya nilai tetap dan promosi mengalami kenaikan satu maka kepuasan konsumen (Y) akan mengalami kenaiakn sebesar 0,243 , jadi semakain baik promosi yang digunakan maka akan sekamik naik kepuasan konsumen.

Tabel 4.2

Hasil Pengolahan Data Koefisien Korelasi Variabel Kualitas Pelayanan $\left(\mathrm{X}_{1}\right)$ Dan Promosi $\left(\mathbf{X}_{2}\right)$ Terhadap Kepuasan Konsumen (Y)

Model Summary

\begin{tabular}{|l|r|r|r|r|r|}
\hline Model & \multicolumn{1}{|c|}{$\mathrm{R}$} & $\mathrm{R}$ Square & $\begin{array}{c}\text { Adjusted R } \\
\text { Square }\end{array}$ & $\begin{array}{c}\text { Std. Error of the } \\
\text { Estimate }\end{array}$ & Durbin-Watson \\
\hline 1 & $.567^{\mathrm{a}}$ & .322 & .308 & 3.754 & 1.620 \\
\hline
\end{tabular}

a. Predictors: (Constant), Variabel X2, Variabel X1

b. Dependent Variable: Variabel Y

Sumber:Data Primer, diolah dengan SPSS.

Dari hasil uji korelasi maka diperoleh nilai r yaitu 0,567 dimana jatuh pada interval 0,400,59 sehingga kualitas pelayanan dan promosi memiliki hubungan yang Cukup Kuat terhadap kepuasan konsumen.

Dasri hasil model summary maka dapat diketahui nilai $r$ square yaitu 0,322 maka dpaat disimpulakan bahwa variable kualitas pelayanan $\left(\mathrm{X}_{1}\right)$ dan promosi $\left(\mathrm{X}_{2}\right)$ berpengaruh terhadap variabel kepuasan konsumen (Y) 32,2\% sedangkan sisanya 67,8\% dipengaruhi oleh factorfaktor lainya yang tidak diteliti dalam penelitian ini.

\section{Uji Hipotesis}

Pengaruh dari masing-masing variabel $\mathrm{x}_{1}$ (kualitas pelayanan) dan $\mathrm{x} 2$ (harga) terhadap keputusan pembelian (y) dapat melihat dari tanda arah dan tingkat signifikansi (probabilitas) ketika semua variabel memiliki arah positif dan memiliki pengaruh signifikan karena nilai signifikansinya $<0,1$ atau $10 \%$. atau dengan nilai signifikansi $0,1, \mathrm{t}$ tabel 1,661 atau $=\operatorname{TINV}(0,1 ; 97)$,adapun hasil pengolahan data menggunakan program SPSS, dengan hasil sebagai berikut:

Tabel 4.3

Hasil Uji Cofficient ${ }^{s}$

Coefficients $^{a}$

\begin{tabular}{|c|c|c|c|c|c|c|}
\hline \multirow{2}{*}{\multicolumn{2}{|c|}{ Model }} & \multicolumn{2}{|c|}{ Unstandardized Coefficients } & \multirow{2}{*}{$\begin{array}{c}\begin{array}{c}\text { Standardized } \\
\text { Coefficients }\end{array} \\
\text { Beta }\end{array}$} & \multirow[b]{2}{*}{$\mathrm{t}$} & \multirow[b]{2}{*}{ Sig. } \\
\hline & & B & Std. Error & & & \\
\hline \multirow[t]{3}{*}{1} & (Constant) & 10.417 & 4.370 & & 2.384 & .019 \\
\hline & Variabel X1 & .526 & .133 & .424 & 3.950 & .000 \\
\hline & Variabel X2 & .243 & .134 & .195 & 1.821 & .072 \\
\hline
\end{tabular}

a. Dependent Variable: Variabel Y

Sumber: Data Primer, diolah dengan SPSS.

1. Pengaruh Kualitas Pelayanan $\left(X_{1}\right)$ Terhadap Kepuasan Konsumen (Y)

Dari hasil pengujian hipotesis diperoleh nilai $\mathrm{t}_{\text {hit }}>\mathrm{t}_{\text {tabel }}$ dan $\mathrm{t}_{\text {sig }}<\operatorname{sig}$, dimna 3,950 $>1,661$ dan $0,000<0,01$. Sehingga dapat dikatakan $\mathrm{H}_{\mathrm{a}}$ diterima dan $\mathrm{H}_{01}$ ditolak dimana "Terdapat pengaruh antara kualitas pelayanan terhadap kepuasan konsumen". Hal ini sejalan dengan penelitian Lola (2018), Siskawati (2019), Chriswardana (2018), I Made (2018), Ghalih (2018).

\section{Promosi $\left(\mathbf{X}_{2}\right)$ Terhadap Kepuasan Konsumen (Y)}

Dari hasil pengujian hipotesis diperoleh nilai $\mathrm{t}_{\text {hit }}>\mathrm{t}_{\text {tabel }}$ dan $\mathrm{t}_{\text {sig }}<\operatorname{sig}$, dimna 1,821 $>1,661$ dan $0,000<0,01$. Sehingga dapat dikatakan $\mathrm{H}_{\mathrm{a} 2}$ diterima dan $\mathrm{H}_{02}$ ditolak dimana 
"Terdpaat pengaruh antara promosi terhadap kepuasan konsumen". Hal ini sejalana dengan penelitian Lola (2018), Chriswardana (2018), I Made (2018).

3. Kualitas Pelayanan $\left(\mathbf{X}_{1}\right)$ dan Promosi $\left(\mathbf{X}_{2}\right)$ Terhadap Kepuasan Konsumen $(\mathbf{Y})$

Adapun hasil pengolahan data pengujian F menggunakan program SPSS, dengan hasil sebagai berikut:

Tabel 4.4

Hasil Pengolahan Data Pengujian F Simultan

ANOVA $^{\text {b }}$

\begin{tabular}{|ll|r|r|r|r|r|}
\hline Model & & Sum of Squares & df & Mean Square & F & Sig. \\
\hline 1 & Regression & 648.090 & 2 & 324.045 & 22.998 & $.000^{\mathrm{a}}$ \\
& Residual & 1366.750 & 97 & 14.090 & & \\
& Total & 2014.840 & 99 & & & \\
\end{tabular}

a. Predictors: (Constant), Variabel X2, Variabel X1

b. Dependent Variable: Variabel $Y$

Sumber: Data Primer, diolah dengan SPSS.

Dari haisl pengujian hipotesis secara simultan diperoleh nilai $\mathrm{F}_{\text {hitung }}=22,998>2,36$ atau ( $F_{\text {hitung }}>F_{\text {tabel }}$ ) sehingga $\mathrm{H}_{03}$ ditolak dan $\mathrm{H}_{\mathrm{a} 3}$ diterima. Artinya "Terdapat pengaruh secara bersama antara Kualitas Pelayanandan Promos terhadap KepuasanKonsumen".. Hal ini sejalan dengan penelitian Lola (2018), Chriswardana (2018), I Made (2018).

\section{PENUTUP}

\section{Kesimpulan}

Dari uraian bab-bab sebelumnya dan hasil analisis dan diskusi, ditarik kesimpulan sebagai berikut:

1. Dari rumusan malasah yang di ajukan maka Terdapat pengaruh yang positif dan signifikan antara kualitas pelayanan terhadap kepuasan konsumen". Hal ini dilihat dari nilai $\mathrm{t}_{\text {hit }}>\mathrm{t}$ tabel dan $\mathrm{t}_{\text {sig }}<\operatorname{sig}$, dimna 3,950>1,661 dan $0,000<0,01$. Sehingga dapat dikatakan $\mathrm{H}_{\mathrm{a} 1}$ diterima dan $\mathrm{H}_{01}$ ditolak.

2. Dari rumusan masalah yang di ajukan maka Terdapat pengaruh yang positif dan signifikan antara promosi terhadap kepuasan konsumen ". Hal ini dilihat dari nilai $t_{\text {hit }}>$ $\mathrm{t}_{\text {tabel }}$ dan $\mathrm{t}_{\mathrm{sig}}<$ sig, dimna $1,821>1,661$ dan $0,000<0,01$. Sehingga dapat dikatakan $\mathrm{H}_{\mathrm{a} 2}$ diterima dan $\mathrm{H}_{02}$ ditolak.

3. Dari rumusan masalah yang di ajukan maka Terdapat pengaruh yang positif dan signifikan secara simultan antara Kualitas Pelayanan dan Promosi terhadap Kepuasan Konsumen ". Hal ini dilihat dari nilia nilai $\mathrm{F}_{\text {hitung }}=22,998>2,36$ atau $\left(F_{\text {hitung }}>F_{\text {tabel }}\right)$ sehingga $\mathrm{H}_{03}$ ditolak dan $\mathrm{H}_{\mathrm{a} 3}$ diterima.

\section{DAFTAR PUSTAKA}

Fandy Tjiptono, dan Gregorius Chandra. (2011). Service, Quality and Satisfaction (ed 3). Yogyakarta.Andi.

Kotler, Philip \& Gerry Armstrong, (2014).Principle Of Marketing, 15th edition. New Jersey:

Pearson Pretice Hall.

Sugiyono (2015).Metode Penelitian Kombinasi (Mix Methods). Bandung: Alfabeta

Sugiyono.(2013). Metode Penelitian KOMBINASI (Mixed Methods). Bandung: Alfabeta.

Sugiyono. (2014). Metode Penelitian Pendidikan Pendekatan Kuantitatif, Kualitatif, dan R\&D. Bandung: Alfabeta

Sugiyono. (2010). Metode Penelitian Pendidikan Pendekatan Kuantitatif, kualitatif, dan $R \& D$. Bandung: Alfabeta. 